\title{
SEQUEL OF STEEL SHAVINGS AND FIBRES ON THE CONDUCTIVITY OF CONCRETE AND ITS PERFORMANCE PREMIUMS THEREOF
}

\author{
Aarif Nazir \\ BE Student, SSM College of Engineering \\ Kashmir, India
}

\author{
Shafaqat Bhat \\ Associate Professor, SSM College of Engineering \\ Kashmir, India
}

\author{
Haya Qazi \\ MTech. Scholar, Sushant University \\ Haryana, India
}

\begin{abstract}
Concrete being the most important construction material has found its place in every nook and corner. The concern of Civil Engineering is to assure the most economic construction with optimum strength and serviceability. This paper deals with the use of steel shaving and steel fibre in concrete to enhance its electric conductivity. A comparative study of the properties of concrete was conducted using steel shaving only, containing steel fibre only and containing both steel shaving and steel fibers. Workability and surface finishability was also used as primary evaluation criteria. Effect on Humans due to flow of current through concrete was also considered.
\end{abstract}

Key Words: Steel Shaving, Steel Fibre, Flexural strength, Electrical conductivity, Workability, etc.

\section{INTRODUCTION}

Concrete, usually Portland cement concrete, is a composite material composed of fine and coarse aggregate bonded together with fluid cement (cement paste) that hardens over time-most frequently a lime-based cement binder, such as Portland cement, but sometimes with other hydraulic cements, such as a calcium aluminate cement. It is distinguished from other, noncementitious types of concrete all binding some form of aggregate together, including asphalt concrete with a bitumen binder, which is frequently used for road surfaces, and polymer concretes that use polymers as a binder.

Aggregate, when mixed together with dry Portland cement and water, the amalgam forms a fluid slurry that is easily poured and molded into the desired shape. The cement reacts chemically with the water and other ingredients to form a hard matrix that binds the materials together into a durable stone-like material. Often, additives (such as pozzolans or superplasticizers) are included in the mixture to improve the physical properties of the wet mix or the finished material. Most concrete is poured with reinforcing materials (such as rebar) embedded to provide tensile strength, yielding reinforced concrete.

Steel fibres and shavings mixed into the concrete can provide an alternative to the provision of conventional steel bars or welded fabric in some applications.

Fibres being used off and on to replace the nominal conventional steel fabric in ground bearing slabs have made their place in construction industries. Steel fibre, which were hitherto neglected, are now immensely being used in suspended ground floor slabs on piles to replace much, and in many cases, all of the reinforcement. Mammoth savings in the cost of endowing and fixing the typical welded fabric reinforcement that is replaced can offset the adjunct cost of adding fibres to the concrete. There will be definitely add-on health and safety sanatives stemming from the reduced handling of reinforcement.

\section{SCOPE}

- The conductivity value of concrete reinforced with steel fibres and shavings is stable with insignificant effects of moisture content, hydration time and temperature on conductivity.

- Being, conductive concrete has a density of about 70 percent that of normal concrete. 


\section{International Journal of Engineering Applied Sciences and Technology, 2021 \\ Vol. 6, Issue 4, ISSN No. 2455-2143, Pages 227-232 \\ Published Online August 2021 in IJEAST (http://www.ijeast.com)}

- Conductive concrete is chemically compatible with normal concrete, bonding well with it if used as an overlay.

- Thermal stability is akin to that of normal concrete.

- The tincture of conductive concrete is darker grey, reflecting its carbon content.

- Conductive concrete is one of the best alternatives to mitigate the problem of snow clearance on bridge decks and airport.

\section{METHODOLOGY}

The electrical conductivity of a particular material is its capability to transfer ions under an electric field. Wet concrete deports like a semiconductor, with its resistivity in the gamut of $10^{5} \Omega-\mathrm{mm}$. whereas dry concrete has resistivity in the range of $10^{12} \Omega-\mathrm{mm}$ acting as an insulator. The disparity in the measured electrical resistivity in wet and dry concrete can be elucidated to fathom out that the electrical conductivity of concrete is a significant upshot of the evaporable water present in it. It can be par suite expected that conductivity elevates with increase in ion transfer, which is an outcome of rise in water cement ratio of concrete. Relocation and convey of ions has to come about significantly for the conductance of electricity in concrete, which can ensue only when a pervious microstructure with copious interconnections. Such a concrete will be extremely permeable engendering an effective transfer of ions. The brininess of the water to be used for mixing concrete greatly sways the electrical conductivity with high water cement ratios. The resistivity is quite small in high strength concrete which is also greatly influenced by its aging, at least for the initial period of curing. For the usual concrete mixes, the water cement ratio varies scantly for a given workability and grading. Thus, the electrical conductivity is influenced by the cement used, because the chemical composition of cement administers the quantity of ions present in the water. Most of the admixtures used seldom elevate the electrical conductivity of concrete significantly. Conductive concrete is a cement-based composite containing a certain quota of electronically conductive elements to procure a stable and relatively high conductivity. In essence, the aggregates normally pre-owned in concrete can be largely put back by a variety of carbon-based substances to execute electrical conductivity in conductive concrete while retaining holding fast to the desired engineering properties. The conductivity of conductive concrete is customarily several orders of magnitude higher than that of normal concrete which is effectively an insulator in the dry state, and has tottering and significantly greater resistivity characteristics than conductive concrete, even when wet. Conductive concrete can be concocted using conventional mixing recipes. The mixing subpoena can be controlled, permitting design of mix formulations that are reliably repeatable, and achieve electrical resistivity values within the overall target design range. The Conductive Concrete, in our case, was fitted with steel plates during laying of concrete in moulds, so that the current can be given a way to set foot in the concrete. Varique was used to increase the voltage gradually and connected to the conductive concrete. The power supply was turned on and the voltage was increased gradually with the help of Varique and the corresponding values of current and voltage were noted simultaneously. The voltage was limited to $200 \mathrm{~V}$.

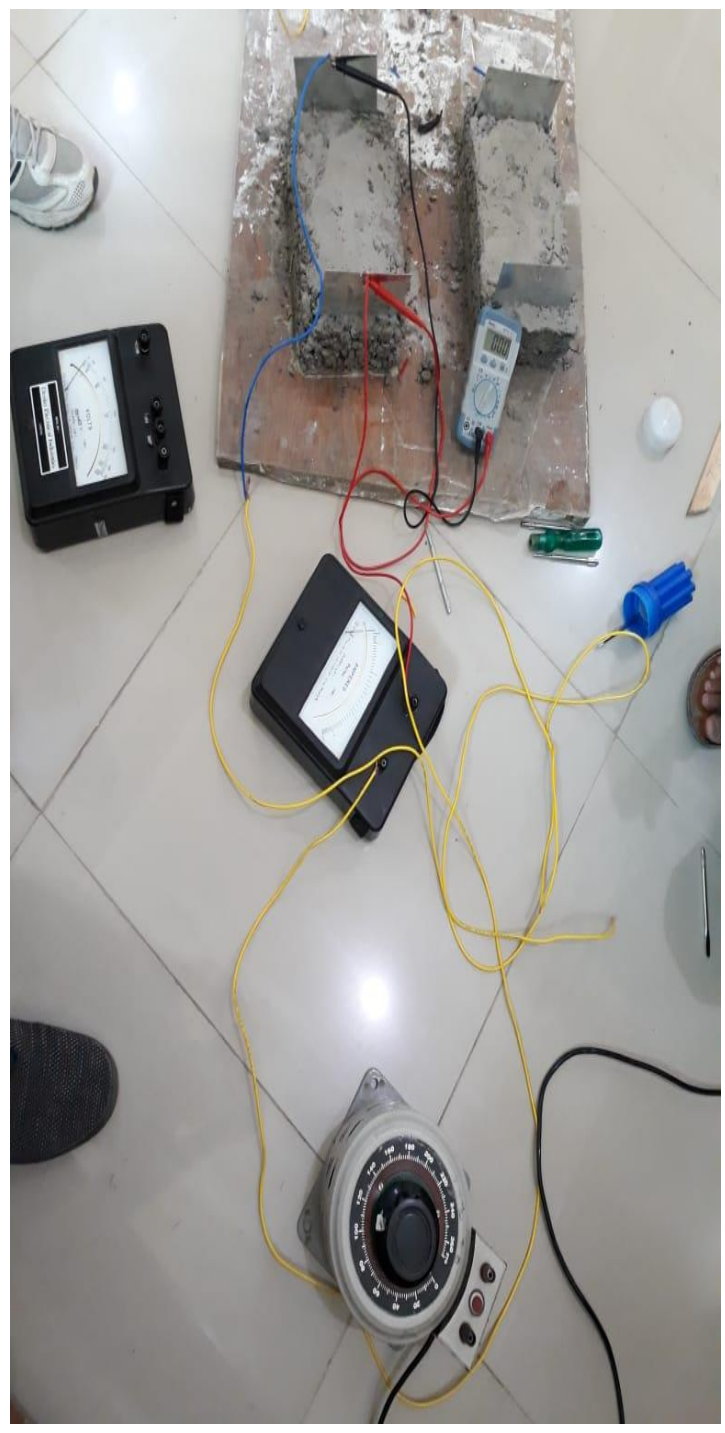



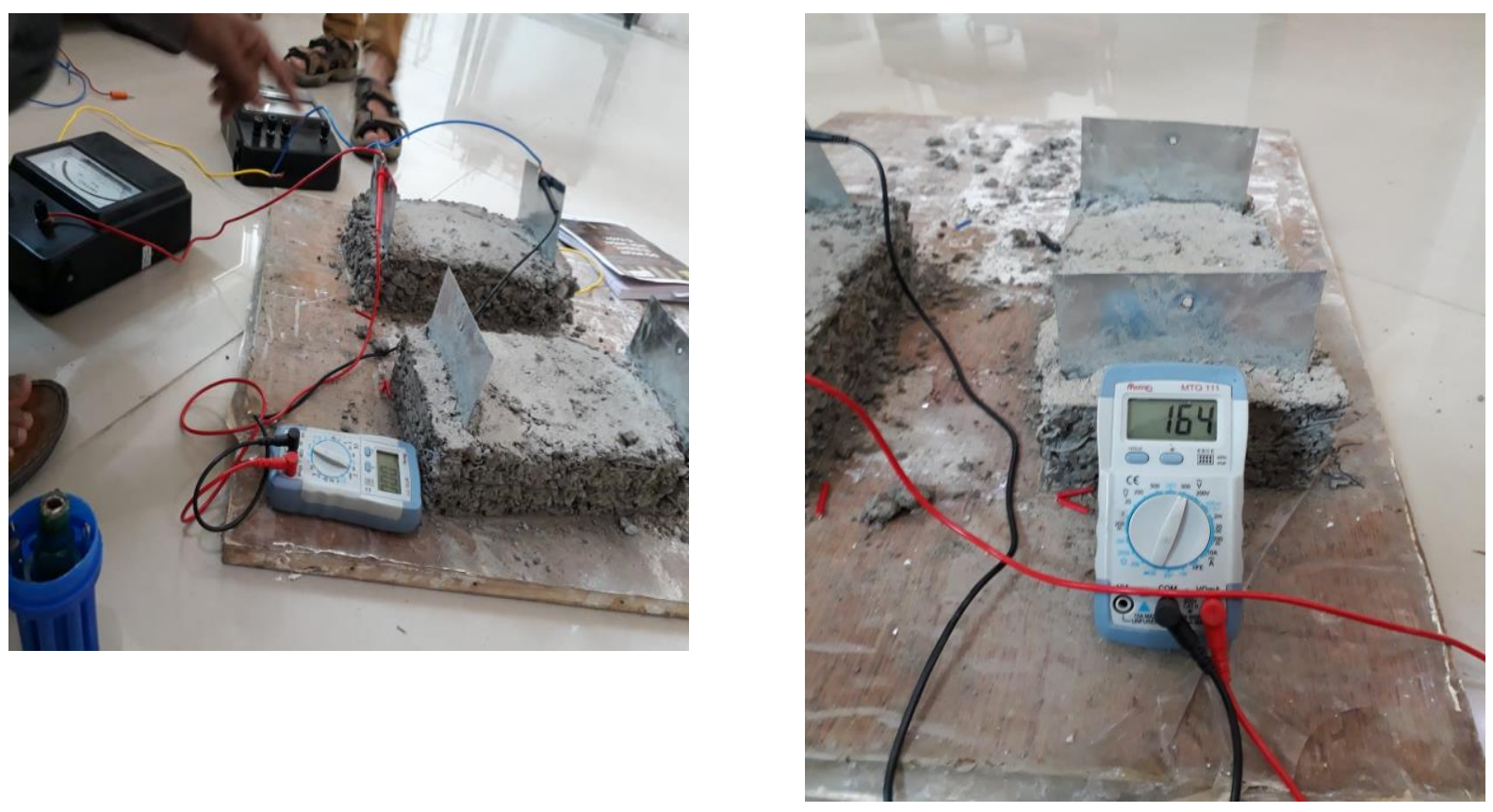

In first two samples quantity of both fibers and shavings was kept same and only size of fibers was varied in order to get the effect of size of steel fibre on breakdown voltage of concrete. In sample I, size of steel fibres was $25 \mathrm{~mm}$ while in sample II, it was $50 \mathrm{~mm}$. In both cases, mix was kept nominal with ratio $1: 2: 4$

The sample specifications are given below:-

\begin{tabular}{|l|l|c|c|c|c|}
\hline S.N & Properties & SAMPLE I & SAMPLE II & SAMPLE III & SAMPLE IV \\
\hline 1 & Size of Sample & 30 X 15 X 5 cm & 30 X 15 X 5 cm & 30 X 15 X 5 cm & 30 X 15 X 5 cm \\
\hline 2 & $\begin{array}{l}\text { Steel Fibre (\% of total } \\
\text { volume) }\end{array}$ & $0 \%$ & $1 \%$ & $2 \%$ & $1 \%$ \\
\hline 3 & Size of Steel fibre (mm) & - & 50 & 50 & 50 \\
\hline 4 & $\begin{array}{l}\text { Steel Shavings ( \% of total } \\
\text { volume) }\end{array}$ & $0 \%$ & $10 \%$ & $10 \%$ & $20 \%$ \\
\hline 5 & Breakdown Voltage & $\begin{array}{l}\text { No current } \\
\text { flows upto } \\
200 \mathrm{~V}\end{array}$ & $30 \mathrm{~V}$ & $85 \mathrm{~V}$ & $29 \mathrm{~V}$ \\
\hline
\end{tabular}

The V-I characteristics of all the four samples are drawn below:- 
International Journal of Engineering Applied Sciences and Technology, 2021 Vol. 6, Issue 4, ISSN No. 2455-2143, Pages 227-232

Published Online August 2021 in IJEAST (http://www.ijeast.com)
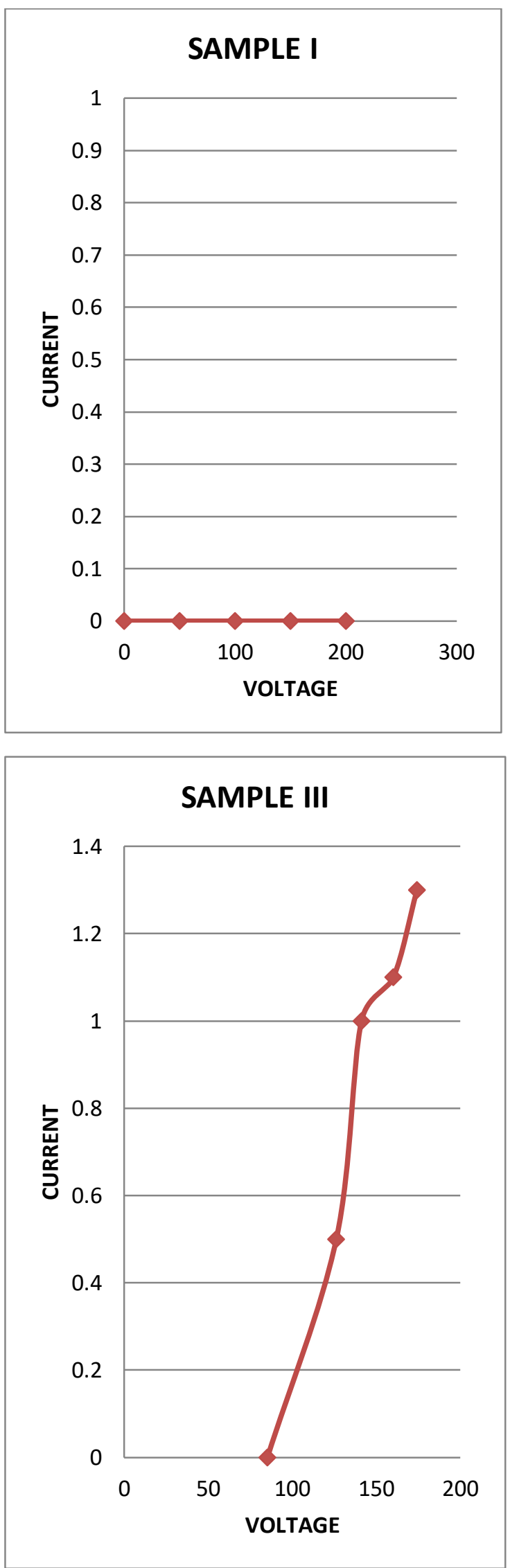

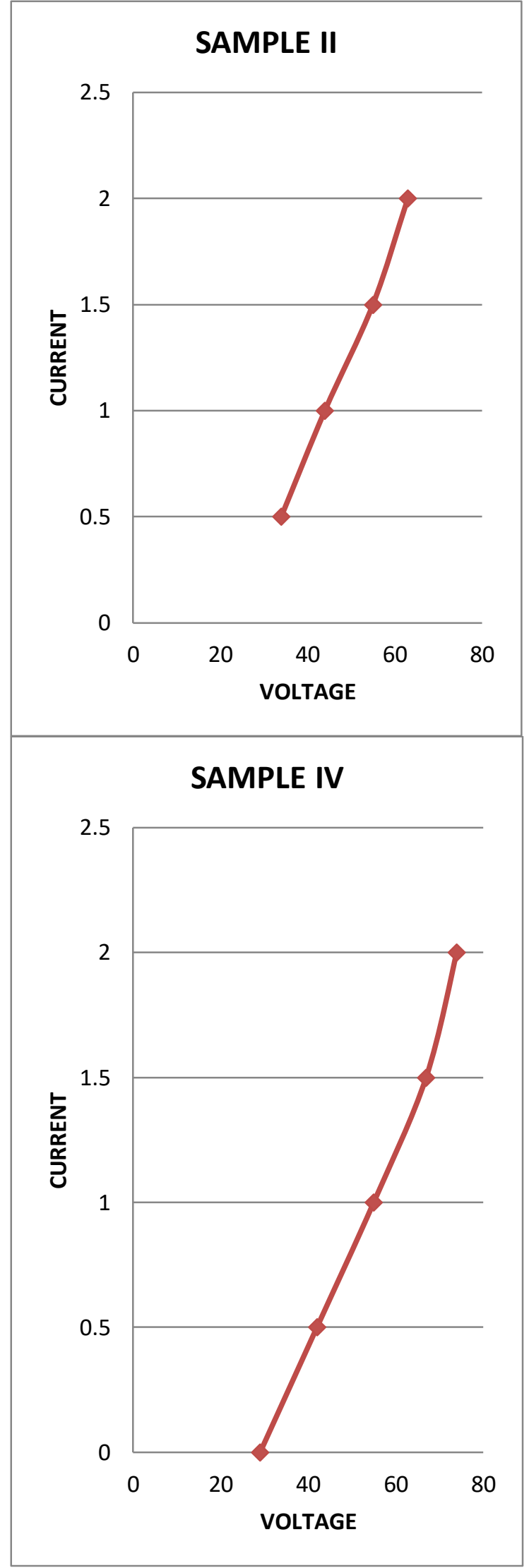

The breakdown voltages obtained from different samples are depicted below:- 


\section{International Journal of Engineering Applied Sciences and Technology, 2021 Vol. 6, Issue 4, ISSN No. 2455-2143, Pages 227-232 \\ Published Online August 2021 in IJEAST (http://www.ijeast.com)}

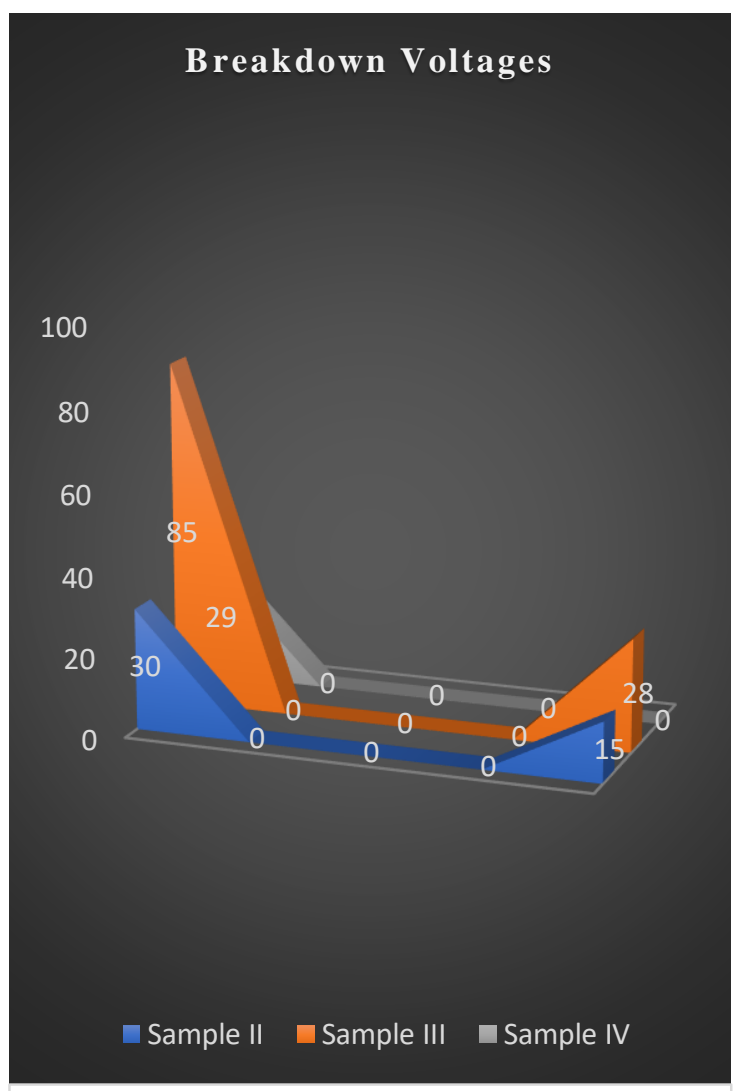

Analysis of Breakdown Voltages

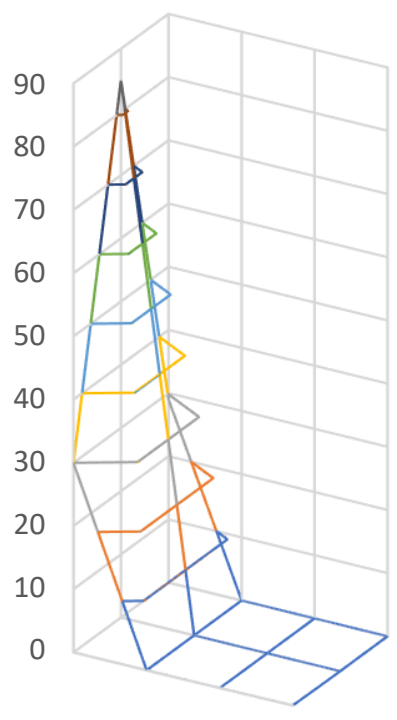

\section{CONCLUSIONS}

1. Use of fibres alone could not increase the conductivity of concrete as it is not possible to have a continuous path for the electric current to flow through the circuit and the conductivity was just same as that of conventional concrete.

2. The use of steel shavings up to $20 \%$ increased the conductivity of concrete but not to the extent that we can call it conductive concrete because the current flowing through the circuit was low and hence, heat production for snow melting could not be achieved.

3. The use of steel shavings and fibres simultaneously increased the conductivity to a greater extent. It is possibly because the steel shavings act as filler conductive material and the fibres as connecting material to provide a path for the electric current to flow.

4. The use of steel chips and fibres simultaneously in concrete can be the best option for its use as conductive concrete (as snow melting and heating system technology).

5. The breakdown voltage for all the samples having both steel chips and steel fibres was within 50 volts, hence conductive concrete of this type can be operated without any risk to Humans due to flow of current.

\section{REFERENCES}

1. Bukovatz J. E., and Crumpton, C. F., 'Kansas' Experience with Interlayer Membranes on Salt-Contaminated Bridge Deck," Transportation Research Record 962, 1984, pp. 66-68.

2. Cress, M. D., "Heated Bridge Deck Construction and Operation in Lincoln, Nebraska," IABSE Symposium, San Francisco, 1995, pp. 449-454.

3. Henderson, D. J., "Experimental Roadway Heating Project on a Bridge Approach,"149 Highway Research Record, No. 14, Publication 111, 1963, pp. 14-23.

4. Jones, R. H., "Developments in the British Approach to Prevention of Frost Heave in Pavements," Transportation Research Record 1146, 1987, pp. 33-40.

5. Kuemmel, D. E., "Managing Roadway Snow and Ice Control Operations," Transportation Research Record, NCHRP, Synthesis 207, 1994.

6. Neville, A. M., Properties of Concrete, Fourth Edition, John Wiley \& Sons, Inc., New York, 1996.

7. Whittington, H., McCarter W., and Forde, M.C., "The Conduction of Electricity through 
Concrete," Magazine of Concrete Research, 33, No. 114, 1981, pp. 48-60.

8. Yehia, S. A., and Tuan, C.Y., "Conductive Concrete Overlay for Bridge Deck De-icing,“ ACI Materials Journal, Vol. 96, No. 3, MayJune 1999, pp. 382-390.

9. Zenewitz, J. A., "Survey of Alternatives to the Use of Chlorides for Highway De-icing," Report No. FHWA-RD-77- 52, May 1977.

10. A.M. Shende, A.M. Pande, M. GulfamPathan. Study on Steel Fiber Reinforced Concrete for M-40 Grade. International Refereed Journal of Engineering and Science (IRJES) Volume 1, Issue 1 (September 2012), PP. 043-048 